\title{
THE INFLUENGE OF THE 6-MONTH COURSE OF NORDIC WALKING ON PATIENT WITH PARKIIISON'S DISEASE - A CASE REPORT
}

\author{
Paula Musiał, ${ }^{1, A, B, C, D, E}$ Monika Michalik, 2, A, B, C, D, E Ewelina Nowak, 2, A, B, C, D, E \\ Justyna Szefler-Derela ${ }^{3, A, F}$ \\ ${ }^{1}$ Student Scientific, Department of Kinesiology, Department of Physiotherapy, Faculty of Health Sciences, Medical University of Silesia \\ in Katowice, Poland \\ ${ }^{2}$ Student Scientific, Department of Sports Medicine and Exercise Physiology, Faculty of Health Sciences, Medical University of Silesia \\ in Katowice, Poland \\ ${ }^{3}$ School of Health Sciences in Katowice, Medical University of Silesia, Department of Physiotherapy, Chair of Physiotherapy, Katowice, Poland

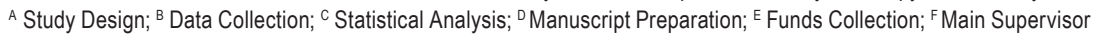 \\ Address for corpespondence: \\ Paula Musiał \\ Medical University of Silesia in Katowice \\ Department of Kinesiology \\ Medyków 12, 40-752 Katowice, Poland \\ E-mail: musial_paula@interia.pl
}

Ahstract A person with Parkinson's disease has bigger problems with maintaining the stability than the healthy person. Nordic Walking is a safe kind of physical activity for elderly people.

The aim of this study is to present the influence of a 6 -month therapy of the Nordic Walking on the imbalance and the risk of falls for 66 -years-old patient with Parkinson's disease.

On the basis of results of 4 tests, performed both at the beginning and at the end of the Nordic Walking therapy, we have made a comparison of patient's changes before and after 6 months of rehabilitation.

the DGI test, the PD patient received 18 points. After he got 22 points. In the Functional Reach Test (FR), while attempting to reach forward, reached out for $23 \mathrm{~cm}$ before the therapy, and $31 \mathrm{~cm}$ after the therapy. In the test and go up the patient got a time of 63 seconds, after therapy the time was reduced to $45 \mathrm{~s}$.

Nordic Walking is a safe kind of physical activity for people with Parkinson's disease. It reduces muscle tension, and improves joint function.

Key Worlls physiotherapy, Parkinson's disease, Nordic Walking

\section{Introduction}

\section{Parkinson's Disease}

Parkinson's disease is caused by chronic, progressive degeneration of the central nervous system. It occurs twice as often for men than for women, mostly in the age group of 40-50 y/o (Struensee, 2010). Symptoms occur when the level of dopamine, the striatal neurotransmitter drops below $60 \%$. The disease causes losses of substantia 
nigra (Krygowska-Wajs, 2006). New treatment strategies are always being developed, like gene therapy and usage of nanotechnology, a new therapeutic method using molecules that can contribute to the regeneration of damaged neurons and drugs transfer through the blood-brain barrier (Maguire-Zeiss, 2008). Characteristic symptoms of the disease are primarily resting tremor, muscles' hypertonia stiffness, slowness of movement (bradykinesia), and abnormal posture. Early detection of the disease allows patients to longer maintain the motor skills, which affects the extension of the period of independence. Physiotherapy, individually adjusted for each patient, should complement the pharmacological fight against the disease. An integral part of the physical activity for each patient should be physiotherapy and physical therapy. In determining the severity of the disease patient assessment scales might be helpful, like Hoehn and Yahr Unified Parkinson's Disease Rating Scale (UPDRS called. Unified Parkinson's Disease Rating Scale) or functional scales (Struensee, 2010).

\section{Disorder of Core Stability for a Patient with Parkinson's Disease}

Core stability depends heavily on the correct functioning of the nervous system. For your body to react properly, the nervous system must quickly respond to the loss of balance (Dyszkiewicz, 2006). Studies, for example those conducted by (Kłoda, 2013), show that patients with PD risk of falls and losing balance is much higher. They performed studies on a group of 43 patients with PD and 46 healthy people and studied their balance maintaining. The research team concluded that increased deviation of the center of gravity makes it more difficult to maintain a balance for sick patients (Zawadka, 2013). Problems with balance show up already in the early stages of the disease. Imbalance can be seen (detected) after balance tests, but they show only the qualitative nature of the disorder, like Tinneti test (Kłoda, 2008). Stiffness and slowness of movement cause loss of balance and increase risk of falls.

Figure of a human suffering from PD becomes inclined, head and torso slide forward, shoulders start hanging. Knees, hips and elbows are flexed in (Petit, Allan, Vermersch, 1997; Samii, 2008). Such a posture can increase the number of falls - retropulsion or propulsion (Kłoda, 2013). Using the physiotherapy, we can decrease the risk of falls and increase the quality of life of patients (Skalska, 2014).

\section{Nordic Walking as a Form of a "Drug" for Elderly}

Nordic Walking is a safe form of physical activity for people with Parkinson's disease. It reduces muscle tension, and improves joint function and motor coordination (Chęcińska-Hyra, 2012). It combines march with pushing back using specially designed poles (Mors $\varnothing$, Hartvigsen, Puggaard, Manniche, 2006). Patient adjusts walking speed according to his abilities. This technique of walking involves $90 \%$ of the body muscles, many of which are not used during normal walking. As a result, the patients does not feel too much fatigued. Using sticks as a support, reduces load on the articular surfaces while walking. This form of movement engages upper and lower limbs and, as a result, improves the asymmetric movements.

\section{Material and methods}

\section{Material}

Patient: male, age 66, 10 years ago diagnosed with Parkinson's disease. $3^{\text {rd }}$ stage of the disease, according to the Hoehn-Yahra-scale. BMI equals 25 , which means a slight overweight. In the early stages of Parkinson's disease patients experienced troubles with writing, micrographia, and degradation of movement. 
In addition, conducted examination found hypomimia (impaired facial expressions) and lack of balance of the upper limbs while walking. MRI of the head and UDP were also performed. The MRI scan noticed a single, nonspecific foci of demyelination in the white matter around the front corner of the left lateral ventricle and subcortical parietal lobes. UDP showed an asymmetry flow in the vertebral arteries $(L>R)$, but without asymmetry in the flow in the carotid and intracranial. In the early stage of disease symptoms touched a right side of the body. At the beginning the man has experienced a tremor of right arm, which was intensifying in stressful situations. Increased tension of gearwheel type in upper limbs and "lead pipe" stiffness in lower limbs were observed. For all his daily activities, patient is forced to dedicate much more time than a healthy person. We observed also a typical for Parkinson's disease stiffened posture - head and torso are inclined forward, arms and legs are slightly bent and arms leaned forward, patient is lacking of counter-rotation of trunk. Very often, while performing ordered tasks, there was a symptom of "frozen" motion. Throughout many years of dealing with the disease there were, according to the patient, alternating periods of higher and lower mobility. What is more, a phenomenon of retropulsion appears very often.

It occurs in both direction gait, and during a steady, uniform march. The doctor conducting the neurological treatment of the patient since 2007 has noticed periodic worsening of mood. Parkinson's disease did not exist in family interview. Along with the progress of the disease, new symptoms may appear.

The medical treatment causes side-effects, like among others dyskinesia (uncoordinated movements of the various parts of the body, unwilling movements). The health condition of the patient may deteriorate with time which is associated with aging and worsening symptoms of Parkinson's disease (Struensee, 2010). Others disorders occurring in Parkinson's disease are: problems with swallowing, difficulties with changing the body position while sleeping, eyelids movements problems. The patient can manifest also psychological symptoms like: depression, cognitive disorders, memory disorders, dementia, sleep disorders. Parkinson's disease is also accompanied by the pain caused by contractures and stiffness (Janocha, Zawilska, 2007). Autonomous system is also later negatively affected, what is associated with the occurrence of orthostatic hypotension. Other problem appearing during the subsequent stages is randomness of "on" and "off" phase - as one of the effects of long-term medical treatment. With time kyphosis may deepen, which will reduce the respiratory function and increase vulnerability to infections (Kwolek, 2009).

\section{Methods}

Patient participated in NW activities from December 2014 for six months. Classes were held once a week. The time of one therapy session was $1.5 \mathrm{~h}$. At the beginning of the 6 -months participation period, fitness tests were organized to verify effects of the therapy. A question was posed: how patient will be influenced by such a form of physical activity, in particular in the area of maintaining balance and coordination improvement. In addition, the goal was to learnt the patient of correct alternating motion of upper and lower limbs and to learnt correct technique of walking with poles. Tests that were conducted at the beginning of the treatment for later verification included:

1. Dynamic Gait Index (DGI) assessing gait, balance, and the likelihood of falling. Patient was able to get 18 points.

2. Functional Reach Test ( FR) is a clinical test, which allows to assess the balance in a standing position . The patient has lean forward with feet and pelvis fixed (not taking them from the ground) 1 . Results of the test are given in centimeters. Patient obtained $23 \mathrm{~cm}$ of reach. 
3. Test up and go is a test designed especially for the elderly after a stroke with spinal injuries and Parkinson's disease . It allows to evaluate gait and balance. The patient obtained a time of 63 seconds.

4. The patient underwent the Tinetti test, part of the balance examination; Sum of points before evaluating the balance part was $11 / 16$.

After verifying these results, the activities of Nordic Walking started.

At first, the respiratory physiotherapy started. Patient was taught of calm and rhythmic breathing: breathing in through the nose and a long, quiet exhaling through the mouth.

During developing of a rehabilitation program, a guidance on respiratory physiotherapy developed by $A$. Patel and others was used (Duncan, Weiner, Chandler, Studensld, 1990). Workout lasted about 10 minutes.

The following is a schematic description of the individual classes:

1. Initially, the number of repetitions breaths wasn't exceeding 6-8 in order to avoid hyperventilation of the patient. Stop of breathing was introduced to the exercises as following: patient was taking a 5-secondslong breath in, then 3 seconds of holding the breath and then 5-seconds-long exhaling. During the exhalation phase, patient tried to remove as much air from the lungs as he could. Over the time, a number of repetitions was increased even to 20 . After demonstrating the exercise, observing its performance by the patient and necessary correction made by authorized medical staff, the patient was able to perform these exercises alone.

2. Patient was taught different breathing tracks: upper-ribbed and abdominal (diaphragmatic). First one was demonstrated by laying the therapist's hands on the upper ribs, pressing them during patient's exhalation, and then releasing when he was exhaling.

3. Diaphragm track was turning on during the exercise in which patient put one hand on a stomach, and the other one on the chest. The latter one was to be kept level, and the first one to move up and down. Successively: breath in through the nose - the hand goes up, exhale through the mouth, the hand goes down. Then the patient blew a lighted candle from $15 \mathrm{~cm}$, and the flame was needed to heave. The distance was increased with each passing day.

4. It was tried to reduce the muscle tension of the chest by lifting the upper limbs, straight at the elbows. This movement was synchronized with inhaling through the nose. The patient lowered upper limbs along the torso during exhaling through the mouth.

5. The patient lifted his arms as high as possible - a movement of shrugging his shoulders. Countdown to three and arms were being lowered.

Scapula were pulled tight, chest pushed out to the front, countdown to three and relaxation.

Then the height of sticks was adjusted. Properly chosen, they should allow 90 degrees flexion at the elbow. Warming up lasted 20 minutes:

- with feet slightly apart, poles were passed from the right to the left hand - 10 reps,

- front, rear and alternately arms circling - 8 reps,

- in standing position, lean on the poles, and do forward and backward swings with right and left lower limb -10 reps,

- position of the patient as above, make the hips circulations, first from the left then from the right 5 repetitions on each side,

- knees circulation, inside and outside, 
- then lift one of your heels and make circular movements of your ankle, first the right one, then the left 5 reps on one side,

- fold your toes alternately with standing on toes -10 repetitions.

After the warm-up we proceeded to walking with sticks. At the beginning, several principles of correct walking were reminded:

- the body works in rotation with the supportive lower limb, so when the right lower limb is as a support, then the left part of the torso moves forward,

- the pivotal movement of the upper limbs synchronized with the movement of the torso,

- rolling the foot starts from heel to toes,

- during the march is an active movement of the upper limbs happens, what affects the rhythm of the march,

- the head looking forward with straight back,

- steps must be alternating, forward and harmonious,

- you should push back from the big toe,

- upper limbs must be kept closely to the body.

The march started with a 10 minute easy gait. Then it was changing from slower to faster movements, longer to shorter steps, walking sideways, starting from the right foot, then from the left. When the patient's gait was economical and alternating the task was made more difficult, by an addition obstacles on the road, e.g. a ball or a tape. Direction of the march was also modified. The therapy for disorder of patient's facial expressions was conducted later. Using the concept of $\mathrm{C}$. Morales, shoulder girdle of the patient was relaxed with the massage. Then there was a return to marching with poles as before, when the pace and direction were being changed and some exercises aimed at improving the quality of gait performed. The final march lasted 10 minutes .

At the end of the session we performed stretching and calming exercises . Each muscle was kept stretched for 20-30 seconds. The aim of this was to reduce the tonicity and calm down the patient, like also increase the range of joints mobility. Those exercises included:

- stretching of the muscles of the lower limbs, mostly sciatic tibial, quadriceps, gluteal,

- stretching of the muscles of the upper limbs,

- limb movements combined with calm breathing at the end,

- free falls of torso.

With time passing, the exercises were refined, the walking speed and level of difficulty of the exercises were also increased.

\section{Results}

After 6 months of practice 4 tests were performed again: Dynamic Gait Index, Functional Reach Test, test and go up and part of evaluating the balance from Tinetti test. Improvement was found in all 4 results (see Table 1). In the case of the DGI before training patient got 18 points and after 6 months 22 points. FR before was $23 \mathrm{~cm}$, and after $31 \mathrm{~cm}$. The time of test up and go before was 63 seconds, and 45 seconds after the therapy. Tinetti test 11/16 and after $13 / 16$. 
Table 1. The results of the influence before and after Course of Nordic Walking on Patient with Parkinson's Disease

\begin{tabular}{lcc}
\hline \multirow{2}{*}{ Type of the test } & & Results \\
\cline { 2 - 3 } & before the test & after the test \\
\hline Dynamic Gait Index (points) & 18 & 22 \\
Functional Reach Test (cm) & 23 & 31 \\
Up and go (s) & 63 & 45 \\
Tinetti test (points) & $11 / 16$ & $13 / 16$ \\
\hline
\end{tabular}

\section{Disculssion}

Results presented in this work indicate an alleviation of the symptoms for a patient with Parkinson's disease. Similar results of studies while using Nordic Walking training were published by I. Reuter and others. As they notice, persons who supervise the exercises, should pay an additional attention to technique of gait with poles.

One of symptoms of the Parkinson's is pain. Regular physical activity along with the walking exercises decrease the pains of back, of sacroiliac joints and of joints of the upper limb. I. Reuter and others compared effectiveness of walking training with Nordic Walking training. After examinations it was stated that gait pattern and stability was much better for those who were training Nordic Walking. After 6 months of Nordic Walking, the gait was longer, which is very important for reducing the risk of falling. Reuter and others stated also positive changes in cognitive functions, concentration and memory for patients taking part in Nordic Walking group training. Regular physical activity decreases negative effects of Parkinson's, including „freezing” of the movement. Rehabilitation supplements pharmacological treatment. Reuter and others showed also that walking training and Nordic Walking training gives better results than using only relaxation and tensile exercises (Reuter et al., 2011).

Studies conducted by J. Szefler-Derela and others point out improvement of gait, dynamical balance and static mobility. After 6 weeks of Nordic Walking training, patients with Parkinson's were better at performing physiotherapist's orders. Improvement of gait pattern for the 66 years old patient were confirmed among others by Dynamic Gait Index test and Up and go test. Those tests were used to grade results in studies by J. Szefler-Derela and others, where the significant influence on the speed of gait was concluded (Szefler-Derela, 2014).

Positive effects of Nordic Walking training is also a general improvement of physical fitness. P. Kocur and others conducted studies on a group of 80 men after acute coronary syndrome. It was proved that even a short-term Nordic Walking training increases endurance and dynamical balance. Gait training with poles increases autonomy and life quality (Kocur, Deskur-Śmielecka, Wilk, Dylewicz, 2009).

For patients with Parkinson's gait pattern is the most important in everyday life. De Dreu and others used elements of music therapy to increase locomotive functions. Physical and rhythmical exercises combined decrease „frozen” movement (De Dreu, Van der Wilk, Poppe, Kwakkel, Van Wegen, 2012). Studies of De Dreu and others may be a hint of how to conduct Nordic Walking classes. Music during the training will influence the speed of gait and make the sessions more diverse.

While treating patients with Parkinson's, physiotherapy must play an essential role during the therapy. Studies conducted by M. Strunsee proved that a proper kinesiotherapy program may decrease various kind of tremors. UPDRS questionnaire defines severity of symptoms for Parkinson's disease. This scale allows to grade for example: manual skills, mimics, tremor, gait pattern and posture stability. Results coined by M. Struensee on the basis of 
UPDRS questionnaire shows that it is possible to soothe symptoms of Parkinson's by regular physical activity (Struensee, 2010).

Aside of the Nordic Walking training, we used also various other exercises (breathing, coordination and flexing exercises). Therapeutic success is guaranteed by the proper choice of exercises, including all rules of kinesiotherapy. Non-weight bearing exercises and weight-bearing exercises with resistance added to the improvement program made by M. Struensee contribute on, among others, to improve manual movements of hands and alternate movements (Struensee, 2010).

During the six month cycle of Nordic Walking training we used also other physiotherapeutic methods, like classic massage. Thanks to the laxity of shoulder girdle, patient could correct his body posture. M. Hernandez-Reif and others point out positive effects of massage. They were comparing effects of the massage and Jacobson's training onto the Parkinson's symptoms. Patients attending the massage sessions got better results of UPDRS. Among those, authors noted also lowered level of stress hormones (norepinephrine and epinephrine). Aside of eliminating stiffness, massage decreased also sleep disorder (Hernandez-Reif, Field, Largie, 2002).

Walking with poles affects physical and mental health of patients. Taking part in group session of Nordic Walking helps fighting with the routine and improves emotional state of patients. Confirmation comes from the studies conducted on the group of 20 patients older than 70 years. Results obtained by Hank Suk and Jeung Hung prove that walking training strengthens patients' leg muscles as well as their cognitive functions. Patients performing only general exercises didn't get that good results as the group using Nordic Walking. Contact with others and fresh air activity decreased depression symptoms for seniors (Han Suk, Jeung Hun, 2015). During Parkinson's development patient may suffer from cognitive disorder. Patients complain on lowered level of mental comfort, including depression (Janocha, Zawilska, 2007). Participation in Nordic Walking training will not only improve the gait pattern but also will affect declines of humor.

Diverse therapy program and physical activity affects positively symptoms for patients with Parkinson's. Complex perceiving of a patient and, noticing his physical and mental needs will affect positively his autonomy and social life. Everyday life comfort comes from working on the gait pattern and manipulative skills. Rehabilitation program must be individualized, but participation in the group sessions also plays a crucial role in the process of improvement.

\section{Consclusions}

6-months long exercises of Nordic Walking significantly improved balance and reduced the risk of fall for the patient. Exercises with NW poles contributed to improving the quality of gait for patients with Parkinson's disease, reducing sense of anxiety associated with the acceleration of walking. In addition, an improvement of joint mobility was confirmed. The posture has become more upright and muscles less tensed. Patient's movement became smoother and faster, so the march with sticks positively influenced the symptom of bradykinesia.

\section{Summary}

Regular physical activity reduces severity of symptoms of people suffering from Parkinson's disease. Group exercises also contribute to the integration of patients who are struggling with the same condition. Cessation of exercise can exacerbate symptoms for given patient, thus worsening the quality of life and sense of independence. 


\section{References}

Behrman, A. (2002). Is the functional reach test useful for identifying falls risk among individuals with Parkinson's disease? Physical Medicine and Rehabilitation, 4, 538-542.

Chęcińska-Hyra, O. (2012). Ocena sprawności kończyn górnych osób z chorobą Parkinsona uprawiających Nordic Walking. Rozprawy Naukowe, 39, 110-112.

De Dreu, M., Van der Wilk, A., Poppe, E., Kwakkel, G., Van Wegen, E. (2012). Rehabilitation, exercise therapy and music in patients with Parkinson's disease: a meta-analysis of the effects of music-based movement therapy on walking ability, balance and quality of life. Parkinsonism \& Related Disorders, 18, 114-119.

Dyszkiewicz, A. (2006). Znaczenie posturometrii i stabilografii w rehabilitacji i zapobieganiu upadkom u osób po udarze mózgu. Zeszyty Medyczno-Naukowe, 127-140.

Duncan, P., Weiner, D., Chandler, J., Studensld, S. (1990). Functional reach: a new clinical measure of balance. J. Gerontol, 45, $192-197$.

Han Suk, L., Jeung Hun, P. (2015). Effects of Nordic walking on physical functions and depression in frail people aged 70 -years and above. Journal of Physcial Therapy Science, 8, 2453-2456.

Hernandez-Reif, M., Field, T., Largie, S. (2002). Parkinson's disease symptoms are differentially affected by massage therapy vs. progressive muscle relaxation: A pilot study. Journal of Bodywork and Movement Therapies, 6, 177-182.

Janocha, A., Zawilska, J. (2007). Zaburzenia snu w Chorobie Parkinsona charakterystyka i leczenia. Via Medica, 1 (7), $14-24$.

Kocur, P., Deskur-Śmielecka, E., Wilk, M., Dylewicz, P. (2009). Effects of Nordic Walking training on exercise capacity and fitness in men participating in early, short-term inpatient cardiac rehabilitation after an acute coronary syndrome - a controlled trial. Clin. Rehabil., 23, 995-1004.

Kłoda, M. (2013). Ocena stabilności posturalnej pacjentów z chorobą Parkinsona. Postępy Rehabilitacji, 5-11.

Krygowska-Wajs, A. (2006). Przedkliniczny i wczesny okres choroby Parkinsona-diagnostykai możliwości leczenia neuroprotekcyjnego. Przegląd Neurologiczny, 177-182.

Kwolek, A. (2009). Fizjoterpia w rehabilitacji neurologicznej. Wrocław: Elsevier.

Maguire-Zeiss, A. (2008). Gazing into the future: Parkinson's disease gene therapeutics to modify natural history. Exp Neurol, 101-113.

Mors $\emptyset$, L., Hartvigsen, J., Puggaard, L., Manniche, C. (2006). Nordic Walking and chronic low back pain: design of a randomized clinical trial. BMC Musculoskeletal Disorders, 7, 77.

Petit, H., Allan, H., Vermersch, P. (1997). Choroba Parkinsona - Klinika i leczenie. Warszawa: Sanmedia.

Reuter, I., Mehnert, S., Leone, P., Kaps, M., Oechsner, M., Engelhardt, M. (2011). Effects of a Flexibility and Relaxation Programme, Walking, and Nordic Walking on Parkinson's Disease. Journal of Aging Research.

Rzepka, A., Kędziora-Kornatowska K., Jakubczyk, M., Budnik-Szymoniuk, M., Glaza, I., Kusza, K. (2011). Rola personelu pielęgniarskiego w fizjoterapii oddechowej. Pielęgniarstwo XXI wieku, 43-46.

Samii, A. (2008). Cadrinal features of Elary Parkinson's disease. Parkionson's Disease - Diagnosis and Clinical Management, 45-53.

Skalska-Dulińska, B. (2014). Rehabilitacja zamrożeń chodu w przebiegu choroby Parkinsona. Aktualna Neurologia, 2, 140-148.

Struensee, M. (2010). Ocena wpływu kinezyterapii na sprawność motoryczną pacjentów z chorobą Parkinsona. Nowiny Lekarskie, 191-198.

Szefler-Derela, J. (2014). Nordic Walking w rehabilitacji choroby Parkinsona. Ann. Acad. Med. Siles, 5, 361-367.

Zawadka, M. (2013). Ocena wybranych parametrów stabilności postawy i funkcji poznawczych osób z Chorobą Parkinsona po 60 r.ż. Hygeia Public Health, 1, 80-85.

Cite this article aS: Musiał, P., Michalik, M., Nowak, E., Szefler-Derela, J. (2017). The Influence of the 6-month Course of Nordic Walking on Patient with Parkinson's Disease - a Case Report. Central European Journal of Sport Sciences and Medicine, 4 (20), 31-38. DOI: 10.18276/cej.2017.4-04. 